\title{
Masonería y fascismo en Italia (1917-1943)
}

\section{Freemasonry and Fascism in Italy (1917-1943)}

\author{
Aldo Mola \\ Profesor en la Universidad de Milán, Italia. Presidente del Centro Europeo para el Estudio del Estado \\ "Giovanni Giolitti" y del Centro para el Estudio de la Masonería en Italia. Correo electrónico: \\ aldoamola@gmail.com
}

DOI: http://dx.doi.org/10.15517/rehmlac.v8i2.10348

Fecha de recibido: 7 de agosto de 2016 - Fecha de aceptación: 14 de octubre de 2016

\section{Palabras clave}

Masonería; fascismo; Mussolini; Italia

\section{Keywords}

Freemasonry; Fascism; Mussolini; Italy

\begin{abstract}
Resumen
En esta conferencia se aborda la relación entre masonería y fascismo en Italia entre 1917 y 1943 . Esta relación fue y es tratada hasta el momento de forma general entre mitos y leyendas, restableciendo en esta ocasión, los principales hitos de su historia. ¿Masonería y fascismo, incompatibles? ¿Cuándo? ¿Cómo? ¿Para quién? Los matices son numerosos y muy importantes para comprender ese periodo, ese lugar, tanto a unos como a los otros que, en no pocas ocasiones, compartieron los mismos nombres y apellidos. Mussolini navegó en aguas turbulentas aprovechándose de las fuerzas de las mismas según le convenía. ¿Qué hizo?
\end{abstract}

\begin{abstract}
At this conference, the relationship between freemasonry and fascism in Italy between 1917 and 1943 has been analyzed. This relationship has thus far been generally shrouded by myths and legends, forcing historians to reconsider the period and the major milestones in its history. Were Freemasonry and Fascism incompatible? When? How? For whom? The nuances are numerous and crucial to understanding that specific time and place, just as in other contexts, which on many occasions shared the same names and features. Mussolini sailed into troubled waters, taking advantage of them as it suited him. What did he do?
\end{abstract}

\section{Premisa. "El fascismo tuvo un alma masónica"}

El 30 de diciembre de 1922, tres meses después de la creación del gobierno de unión nacional presidido por Benito Mussolini, duce del fascismo, Domizio Torrigiani, gran maestro del Grande Oriente de Italia afirmó que la "Revolución (fascista) tiene un alma masónica". Esta declaración tiene una importancia fundamental. La masonería siempre había dicho que era el alma de todas las revoluciones; políticas, culturales, morales. Según Mussolini la conquista del poder por el Partido Nacional Fascista era una revolución, una ruptura histórica. El 31 de diciembre de 1922 el gobierno italiano (que contaba solo con 4 fascistas entre sus 15 ministros) acuñó una moneda con el rey por un 
lado y el fascio por el otro. El nuevo calendario empezó a contar a partir del año I de la "Era fascista", a semejanza de la República francesa desde 1792.

El gran maestro Torrigiani reconoció así que el fascismo era el autor de la Revolución italiana y expresión del espíritu masónico.

Antes de recorrer la historia institucional y política de los años del periodo fascista es preciso sentar unas premisas acerca del significado de los términos "fascismo" y "masonería".

El fascismo es el nombre (una etiqueta) usado para definir la época de la historia italiana que transcurre entre 1919 y 1943, y sobre todo desde la "marcha sobre Roma" hasta la caída de Benito Mussolini (1922-1943/1945), y para indicar una concepción y una práctica del poder. Pero el término "fascismo" también se emplea como sinónimo de dictadura, de régimen totalitario, de Estado policial. En realidad en Italia, a diferencia de lo que ocurrió en la Unión Soviética con Stalin y en Alemania con Hitler, el gobierno nunca fue una dictadura personal ni un totalitarismo. El fascismo fue un régimen autoritario de partido único, pero el Partido Nacional Fascista resultó estar profundamente dividido internamente y nunca tuvo un proyecto ideológico, político, económico y social unívoco. Por eso el término "fascismo" hay que utilizarlo con mucha prudencia para evitar confusiones. Su uso es fuente de errores, incluso graves porque a menudo se combina con "nazi-fascismo", una etiqueta que tiene su origen en la polémica política, pero que carece de todo tipo de fundamento histórico, ya que nunca ha existido ni una doctrina ni un sistema político "nazi-fascista". Incluso tras la alianza militar con Alemania (el Pacto de Acero, el Eje Roma-Berlín) el sistema político-institucional italiano se mantuvo profundamente distinto del alemán. Lo mismo puede decirse del Pacto Antikomintern o Tripartito (Roma-Berlín-Tokio), dadas las insuperables diferencias institucionales, políticas, culturales y sociales de los tres países que lo formaban. En particular cabe recordar que el racismo de la Alemania hitleriana fue un racismo biológico, mientras que las leyes raciales aprobadas en Italia a partir de 1938 fueron expresión de un racismo ideológico.

Para evitar errores y confusiones, hay que recordar que en Italia el fascismo nunca fue una filosofía, una doctrina política, ni siquiera un sistema de gobierno. Aunque, como ya se adelantó, la palabra fascismo con el paso del tiempo se convirtió en sinónimo o símbolo de dictadura y totalitarismo, la realidad histórica es completamente distinta. En los veinte años durante los que gobernó Mussolini hubo 117 cambios de ministros y 164 de subsecretarios. La política exterior, militar y económica sufrió continuas y profundas transformaciones. Por eso el fascismo no puede ser considerado como un unicum continuo homogéneo a lo largo del tiempo.

La masonería en Italia nunca ha tenido una identidad unitaria. Entre el siglo XVIII y el siglo XX en la península italiana existieron muchas y diversas organizaciones masónicas, con largos periodos de ausencia, en particular tras la Restauración y el 
nacimiento del reino de Italia (1792-1800 y 1814-1861) y con la llegada del régimen fascista (1925-1943/1945).

Entre la Unificación y 1925 la principal organización masónica se denominaba Grande Oriente de Italia (GOdI), nombre ya utilizado en el periodo napoleónico para denominar a las logias del reino lombardo-véneto, dependiente del Imperio francés (18051814), llegando a contar con unos 4000 o 5000 afiliados hasta finales del siglo XIX y en torno a unos 15000 o 25000 entre 1905 y su disolución en 1925.

La conducta de las asociaciones masónicas italianas (Grande Oriente de Italia y Gran Logia de Italia, GLdI, nacida entre 1898 y 1910 no es representativa de la masonería como tal y tuvo unas características propias, distintas de las de otros países (Gran Bretaña, Francia, Bélgica, Alemania, Países Bajos...), diferentes unas de otras: monárquicas, republicanas, revolucionarias...

En 1862 el Grande Oriente de Italia, que mantenía fraterna relación con el de Francia, solicitó el reconocimiento a la Gran Logia Unida de Inglaterra (GLU), pero solo obtuvo la concesión del intercambio de información con su secretaría. Fue reconocido en 1872 y solo durante veinte años. Posteriormente la GLU reconoció (y sigue reconociendo) a la Gran Logia Regular de Italia, creada por Giuliano Di Bernardo en 1994, el cual había sido hasta un mes antes gran maestro del GOdI y que posteriormente dimitió también de la GLR de Italia.

\section{El Estado italiano durante el fascismo}

En Italia el poder soberano entre 1922 y 1943, es decir durante el gobierno de Mussolini y el verdadero "régimen fascista" (desde 1926), se mantuvo en las manos del rey, "órgano supremo del Estado", en la persona de Víctor Manuel III de Saboya (Nápoles, 1869-Alejandría, 1947), quien lo ejerció de acuerdo con el Estatuto, la carta constitucional del reino de Cerdeña desde 1848 y del reino de Italia desde 1861 hasta la aprobación de la Constitución republicana el 1 de enero de 1948.

Fue el rey quien confió a Mussolini la formación del gobierno el 30 de octubre de 1922 y también fue el rey quien impuso su dimisión el 25 de julio de 1943, cuando Italia ya estaba invadida por los angloamericanos y había perdido la guerra. En veinte años el "duce del fascismo" ejerció el poder como presidente del Consejo de ministros y luego como jefe del gobierno, pero siempre en nombre del rey.

El rey nombraba a los ministros, embajadores, altos mandos militares, funcionarios. El Estado se basaba en la monarquía. El Partido Nacional Fascista (PNF) organizó el control de las "masas" pero nunca llegó a conquistar el Estado.

La monarquía, por su parte, siempre había dominado el Senado, cuyos miembros eran nombrados por el rey y eran de carácter vitalicio. Muchos senadores se mantuvieron abiertamente antifascistas y la mayoría apreció la labor de orden público, social y 
económico desarrollada por Mussolini, pero desde una posición "afascista", es decir sin adhesión a la "doctrina del fascismo", que por otra parte cambiaba constantemente.

\section{Benito Mussolini, un "hombre a la búsqueda"}

Mussolini (1883-1945), nació en Predappio (provincia de Forlì, en la región de Romaña, la cual hasta 1860 formaba parte de los Estados de la Iglesia). De joven militó en el partido socialista italiano. De formación libertaria, era anticlerical y socialista revolucionario. Fue encarcelado por haber intentado evitar el envío de militares a la guerra de Italia contra el imperio turco por la soberanía de Libia (1912), aceptada por los socialistas reformistas (muchos de los cuales eran masones y que en 1912 fueron expulsados del Partido socialista precisamente a petición suya). Autor de novelas anticlericales, en el congreso del Partido Socialista italiano de abril de 1914 consiguió que los masones fueran expulsados del partido porque según él obstaculizaban la lucha de clases e impedían la "revolución" maximalista y republicana. Cuando Víctor Manuel III fue objeto de un atentado, Mussolini dijo que habían sido los "inciertos del oficio" (1912).

Tras el estallido de la guerra europea (julio-agosto 1914), Mussolini se posicionó contra la neutralidad proclamada por el Partido Socialista italiano y defendió la intervención de Italia junto a la Triple Entente, sobre todo en defensa de Francia, que era republicana y anticlerical, contra la monarquía austrohúngara, católica y conservadora. Fundó el diario "Il Popolo d'Italia", con la ayuda financiera de empresarios y banqueros. Según algunos, como Cesare Rossi y Eugenio Chiesa -masones-, obtuvo incluso una considerable financiación por parte del Grande Oriente de Francia.

\section{EI Grande Oriente de Italia a favor de la intervención}

En el verano de 1914 el Grande Oriente de Italia, que desde hacía diez años estaba presidido por Ettore Ferrari, se declaró a favor de la intervención italiana contra AustriaHungría. Estaba seguro de poder tomar las riendas de un amplio abanico de partidos, movimientos y asociaciones: socialistas reformistas, radicales, republicanos, demócratas, sindicalistas, asociaciones de "irredentos" ("Trento y Trieste", "Dante Alighieri"), garibaldinos e incluso de carbonaros. Pero cada movimiento tenía ya su propio programa. Se produjo un concurso para ver quién gritaba más alto para conquistar el consenso de la plaza más que el de los electores.

Los líderes del GOdI (mazzinistas y antimonárquicos, como Ettore Ferrari, Giuseppe Meoni, Gino Bandini y, más prudente, Ernesto Nathan, ex-alcalde de Roma), amenazaron a la Corona: guerra o revolución. La consigna ya era un clamor.

Algunos masones (Ferrari, Ferdinando Martini, Salvatore Barzilai, judío...) tuvieron un papel decisivo para que Italia pasara de la alianza con los imperios centrales a la Triple Entente (acuerdo secreto de Londres del 26 de abril de 1915), para humillar al Parlamento y para decidir la intervención, aunque inicialmente solo contra Austria-Hungría, en violación 
del acuerdo. La guerra no duró unas pocas semanas, contra lo que creían el presidente del Consejo de Ministros, Antonio Salandra, y el ministro de Asuntos Exteriores, Sidney Sonnino, (que actuaban de acuerdo con el rey) sino que duró desde mayo de 1915 hasta noviembre de 1918. En aquellos años el poder no lo ejercían los gobiernos, que eran débiles (Salandra, Paolo Boselli, Vittorio Emanuele Orlando), sino más bien la enorme "máquina militar" (cinco millones y medio de soldados), a las órdenes del Comandante Supremo, Luigi Cadorna y posteriormente de Armando Díaz, sujeta al poder financiero e industrial, pero carente de un proyecto político claro y coherente.

Una parte de los intervencionistas (socialistas reformistas, demócratas, garibaldinos...) quería coronar el Risorgimento, es decir alcanzar las "fronteras naturales" que todavía seguían en poder de la monarquía austrohúngara (Trento, Trieste, Istria...). Otros en cambio (nacionalistas, altos mandos, industriales...) deseaban construir el "imperio": el dominio de Italia en el Adriático frente a los eslavos y en el Mediterráneo frente a franceses e ingleses.

Como casi todos los políticos italianos, tanto Mussolini como los nacionalistas se ocuparon poco del reino de España, que consideraban al margen de Europa, en parte porque se mantuvo neutral, a diferencia de Portugal, dependiente de Gran Bretaña.

\section{El fascismo llega al poder}

El término "fascio" (de origen latino) lo usaban los revolucionarios franceses, sobre todo los jacobinos a finales del siglo XVIII, y se mantuvo en uso durante el periodo napoleónico. En Italia a partir de 1870 el "fascio" (el "haz" en español) empezó a usarse en el lenguaje político por los "demócratas" (republicanos, radicales, garibaldinos, mazzinistas, librepensadores), evocando a la Roma antigua: el "fascio" contiene el hacha para decapitar al enemigo. Las bases doctrinales de los "fasci democráticos" garibaldinos, radicales, etc., fueron la lucha contra la Iglesia católica y la creación de la república.

En noviembre de 1917 se creó el "Fascio Parlamentario de Salvación Nacional", el cual organizó un "frente interno" para combatir y terminar con los neutralistas, socialistas, católicos y liberales, seguidores de Giovanni Giolitti (1842-1928), que habían sido contrarios a la intervención en la guerra y se les acusaba de sabotear la victoria. El Fascio Parlamentario incluía a nacionalistas, demócratas intervencionistas, radicales, socialistas reformistas, republicanos y a muchos masones -sobre todo del GOdI- que se ilusionaron de tener su control, pero sobre todo tras el congreso de París, de las masonerías de los países de la Entente y de los neutrales (28-30 junio de 1917), fue a su vez acusado de servir a los intereses extranjeros, especialmente de Francia.

El 23 de marzo de 1919 Mussolini fundó en Milán los Fasci de combate, con la adhesión de excombatientes, audaces, socialistas, radicales, republicanos, sindicalistas y masones ("una centuria" afirmó el gran maestro Domizio Torrigiani) del Grande Oriente y de la Gran Logia de Italia. La sede para fundar el fascio fue facilitada por Cesare Goldman, 
masón y judío. Su programa (muy vago) era republicano y social-nacionalista, en contraposición al socialismo, tanto moderado como revolucionario, y al bolchevismo ruso, duramente criticado por la masonería (incluso con artículos de Ernesto Nathan y declaraciones del nuevo gran maestro del GOdI, Domizio Torrigiani, y del de la GLdI, Raoul Vittorio Palermi). Expresión de la pequeña y mediana burguesía y de los militares, despreciados por la izquierda, el movimiento fascista contó con el apoyo financiero de industriales y banqueros y fue respaldado por las fuerzas del orden (militares y seguridad pública), como respuesta al "bienio rojo", es decir a la ola de huelgas y de violencia que culminó con la ocupación de fábricas (septiembre de 1920) y el nacimiento del Partido Comunista de Italia, sección de la Tercera Internacional fundada en Moscú por Lenin, sobre la base de los Veinte Puntos, a los que posteriormente se añadió la incompatibilidad con la masonería, expresión de la burguesía reaccionaria (y del fascismo).

En el congreso de Roma de noviembre de 1921 el movimiento fascista se convirtió en el Partido Nacional Fascista, con un programa político, económico y social todavía muy confuso.

Entre 1918 y 1922 ninguno de los siete gobiernos de corta duración (Orlando, Nitti I y II, Giolitti, Bonomi, Facta I y II) pudo solucionar el enorme endeudamiento del Estado ni el desorden social generados por la guerra.

En septiembre de 1922 Mussolini declaró que el PNF no pedía la abolición de la monarquía. Como ya había hecho Mazzini, al que citó, la solución de la cuestión institucional, es decir la opción entre monarquía y república, se aplazaba para otro momento futuro, justo como había hecho la masonería desde 1860. El GOdI intentó siempre que hubiera de los suyos en el seno del gobierno del rey, pero sus grandes maestros se declararon todos ellos siempre mazzinistas. Este fue el caso de Adriano Lemmi, Ernesto Nathan y Ettore Ferrari, que eran de los más destacados (1885-1921).

Mussolini, de manera muy reservada pero segura, hizo saber al Pontífice, Pío XI, que el fascismo no pretendía hacer una política contraria a la Iglesia católica. Como se verá más adelante, mantuvo su palabra: evitó la quiebra del Banco di Roma y ordenó que en las aulas escolares y en las oficinas públicas (ayuntamientos, juzgados, etc.) se colocara el crucifijo.

En el Congreso de Nápoles (24 de octubre) Mussolini amenazó con movilizar las escuadras fascistas contra el gobierno. La movilización tuvo lugar en varios centros en la tarde del día 27. Pero Roma, al igual que otras regiones enteras, se mantuvo tranquila, bajo el control de los prefectos y los mandos militares, a los que en algunos casos se les transfirió la tarea de la defensa del orden público.

En definitiva, nunca hubo ninguna "Marcha sobre Roma". Por eso el rey no proclamó el estado de asedio, inútil y contraproducente y, por indicación de todos los partidos constitucionales, de los poderes económicos y de la Iglesia, el 30 de octubre confió a Mussolini la formación del gobierno: una coalición nacional que incluía a nacionalistas, 
fascistas, socialdemócratas, católicos, liberales, demócratas y de la que solo en el último minuto se excluyó al socialista Gino Baldesi. Ministros de la Guerra y de la Marina, fueron el general Diaz, duque de la Victoria y el almirante Paolo Thaon de Revel, luego duque del Mar, y masón de la GLdI.

En noviembre el gobierno obtuvo el voto ampliamente favorable de las Cámaras (diputados y senadores) y elaboró un gigantesco plan de reformas que contó con el apoyo del país.

\section{La masonería italiana apoyó la creación del gobierno Mussolini}

El GOdI y la GLdI apoyaron la llegada del gobierno Mussolini, expresión de la "Victoria" y, por lo tanto de la entrada en la que el Grande Oriente tenía un mérito propio.

Sin embargo la intervención también la habían deseado muchos otros "sujetos", sobre todo los nacionalistas, socialistas reformistas, demócratas e irredentistas.

El gran maestro del GOdI, Torrigiani, el 21 de noviembre de 1921 aprobó la inscripción de los masones en los fasci para orientarlos a favor de la masonería. El 19 de octubre de 1922 afirmó que los masones eran "cada vez más numerosos en los Fasci”. El 3 de noviembre deseó públicamente a Mussolini que "superara la prueba de la manera más gloriosa para la Patria".

En el gobierno también había masones, tanto del GOdI como de la GLdI, pero su línea no la decidían los líderes de las masonerías, ni siquiera la base del PNF, sino un restringido círculo de jerarcas, teniendo la influencia prevalente de la Asociación Nacionalista y de economistas de orientación liberal.

Los nacionalistas fueron los únicos que tenían un proyecto político claro: la conquista del Estado para construir el Imperio Italiano e imponer en el país una disciplina férrea para formar a los italianos de acuerdo con una doctrina, que reunía la tradición romana, la modernidad y la visión social de la nación (Enrico Corradini, Luigi Federzoni, Alfredo Rocco, Roberto Forges Davanzati, Giovanni Giuriati...).

Si bien con profundas diferencias, el programa de los nacionalistas incluía gran parte del programa de la masonería. La diferencia consistía en el hecho de que la masonería (sobre todo el GOdI) reivindicaba de manera genérica los principios de libertad (aunque no hizo ninguna defensa del Parlamento ni del parlamentarismo) mientras que los nacionalistas pedían orden y disciplina en nombre de la nación. De ninguna manera podían existir en Italia dos "partidos nacionales".

La liza entre nacionalistas y masones tuvo lugar entre diciembre de 1922 y febrero de 1923, quedando como ganadores los primeros.

El 30 de diciembre de 1922 Torrigiani afirmó que "todo masón (...) ayuda desde su puesto al Gobierno" y que "esta Revolución (fascista) tiene un alma masónica". El 28 de enero de 1923 declaró a la Asamblea general del Grande Oriente que los masones eran "una 
milicia, no una hermandad", que desde hacía un siglo guiaban la vida nacional, habían luchado contra el bolchevismo y los clericales y ahora apoyaban al gobierno fascista "motor de la reacción contra las democracias parlamentarias degeneradas". En un comunicado afirmó que la Asamblea general había registrado una "notabilísima representación de los jóvenes fascistas". Una nota de la agencia "Volta" (fascista) respondió que el gobierno había restaurado los crucifijos en las escuelas, que la "libertad" defendida por la masonería había llevado a la derrota de Caporetto (1917) y que la "famosa soberanía nacional" masónica era una "vaga mentira convencional".

El 12 de febrero de 1923 el Gran Consejo del Fascismo (instituido por Mussolini como laboratorio de las leyes a presentar ante las cámaras) deliberó la incompatibilidad entre la militancia en el PNF y la afiliación a las logias.

En marzo de 1923, tras largas tratativas, la Asociación Nacionalista (que contaba con más de 60.000 voluntarios armados, los "Siempre preparados", netamente monárquicos, a menudo en lucha contra la milicia fascista) se fundió definitivamente con el Partido Nacional Fascista. En la base del pacto radicaba precisamente la decisión antimasónica del Gran Consejo. Caso único, dicha decisión no fue aprobada por unanimidad porque entre los jerarcas del fascismo (a diferencia de lo que ocurría entre los nacionalistas) había muchos masones: Italo Balbo, Cesare Rossi, Giacomo Acerbo, Alessandro Dudan. Otros líderes masones, como Roberto Farinacci, votaron a favor. El fascismo contaba además con muchos militares masones, activos o en letargo, como los generales Luigi Capello (ex-comandante del Segundo Ejército, Gustavo Fara, héroe de la guerra de Libia, Sante Ceccherini...).

\section{¿Qué era la masonería a la llegada del fascismo?}

Desde 1906 la Constitución del GOdI afirmaba que la masonería italiana era una "Orden que tenía como principio el orden democrático y social" contra cualquier privilegio, luego también contra la monarquía. Su "manifiesto" era el Libro del massone italiano de Ulisse Bacci (ed. 1908-1911), director y propietario de la Revista Masónica, que falleció con los sacramentos católicos después de una vida anticlerical. La primera parte del Libro es un cúmulo de leyendas y fantasías; la segunda, aunque fundamentada documentalmente, identifica la masonería con el Risorgimento, el patriotismo y el mazzinismo. Lo mismo hizo la otra obra importante: Carboneria e Massoneria nel Risorgimento italiano de Giuseppe Leti (1925).

Con Ernesto Nathan como Gran Maestro (judío no practicante y mazzinista) y, más aun con Ettore Ferrari (mazzinista y miembro del Círculo de los Derechos Humanos, una secta secreta netamente contraria a la monarquía), la masonería italiana se identificó con la "cuestión nacional italiana", con el anticlericalismo militante y pidió que se prohibieran las clases de religión católica en las escuelas públicas. En cambio, la Gran Logia de Italia, fundada por el pastor protestante Saverio Fera, se mantuvo fiel a la tradición de la 
Constitución de Anderson y del Rito Escocés Antiguo y Aceptado, que era contrario a que se trataran en la logia cuestiones de carácter político y religioso.

El 9 de marzo de 1923 Torrigiani difundió una circular en la que reivindicaba la identidad entre la masonería y el Risorgimento. Lo mismo hizo el soberano del Rito Escocés, Ettore Ferrari, el cual añadió: "No guardamos rencor al joven Partido (fascista) que, en la confusión de la acción, tal vez todavía no ha encontrado el sosiego de una meditación tranquila (...). El fascismo nos seguirá encontrando de su lado, no codiciosos sino desinteresados colaboradores, si sigue las vías marcadas para Italia por su tradición".

Asimismo la "Associazione italiana del Libero Pensiero" (racionalista y que incluía a ateos militantes) apoyó la llegada del fascismo, como documenta el anuario de "La Ragione", en cuya portada publicó la cúpula de San Pedro coronada con el haz de lictores (fascio littorio) en lugar de la cruz y marcó el 28 de octubre como el día más importante y festivo de la historia de Italia. Así pues, el "mito" de la Marcha sobre Roma (precisamente el 28 de octubre) fue una invención de los fascistas y de sus adláteres.

Como ya se indicó anteriormente, la Asociación Nacionalista facilitó al fascismo un programa coherente y efectivo. Dicha asociación desde hacía diez años dirigía la guerra contra la masonería. Los nacionalistas vencieron porque usaron al Partido fascista que garantizaba el Estado y a las masas, mientras que la masonería no tuvo el control de ninguno de ellos, sino tan solo de los cuadros intermedios de la pequeña y mediana burguesía. El fascismo llegó a contar con más de 3.000.000 de inscritos en el partido y más de 10.000.000 en las demás organizaciones del régimen, pero esto en 1943, poco antes ya de su caída. En el momento de su derrota casi nadie se alzó para defenderlo. El número no significaba que tuviera fuerza.

A diferencia de lo que se ha dicho hasta ahora, el GOdI no obtuvo ninguna ayuda del exterior, ni de Francia ni de Gran Bretaña, ni de la Gran Logia del Estado de Nueva York como tal. Solo alguna pequeña aportación económica a título personal.

La GldD gozaba del reconocimiento de los Supremos Consejos de las Jurisdicciones escocesas de los Estados Unidos, que no obstante nunca interfirieron en cuestiones de política interna italiana y que en todo caso no tenían motivo para cuestionar las decisiones de los poderes constitucionales: el rey, que había nombrado al gobierno y el Parlamento, que lo había aprobado y que luego decidió la reforma de la ley electoral que sustituyó el reparto proporcional de los escaños por el sistema mayoritario. Los Supremos Consejos de Estados Unidos (que reconocieron a la GldI pero no al GodI) aprobaron no obstante el gobierno de Mussolini, ya que combatía a los socialistas revolucionarios y a los comunistas, y respetaba las religiones, empezando por la católica, pero al mismo tiempo defendía el carácter laico del Estado. 


\section{La masonería al margen de la ley}

La masonería italiana se vio así aislada y superada por el fluir de la historia. Entre 1922 y 1924 las dos obediencias siguieron teniendo cada año miles de nuevos iniciados, pero el PNF registraba decenas de miles y el gobierno contaba con el favor del Parlamento y del país. Esto quedó patente con las elecciones de abril de 1924, que otorgaron a la Lista Nacional el $66 \%$ de los votos y los dos tercios de los escaños. La victoria del "Listone" fue tan amplia que de 535 diputados, solo 227 estaban inscritos en el PNF (y muchos de ellos lo estaban desde hacía tan solo unos pocos meses). Los demás diputados elegidos en el Listone eran simpatizantes (liberales, demócratas, católicos). El rey nombró senadores a muchos demócratas, radicales y diputados socialistas, todos ellos convencidos de que el nuevo gobierno garantizaba el orden a nivel interno y la credibilidad a nivel externo. En 1924 incluso la Unión Soviética cerró acuerdos comerciales con la Italia mussoliniana, ignorando al Partido Comunista italiano y más aun a los socialistas, ya fueran maximalistas o el Partido Socialista oficial de Filippo Turati y Giacomo Matteotti, que para entonces ya solo contaba con el $5 \%$ de los votos.

El 10 de junio de 1924 fue secuestrado y asesinado el diputado socialista Giacomo Matteotti: un homicidio preterintencional ejecutado por una "escuadra" de fascistas, tres de los cuales eran ex masones, empezando por su líder, Amerigo Dùmini, que pertenecía tanto al GOdI como a la GLdI. Sin embargo, los constitucionalistas (incluido el filósofo liberal Benedetto Croce) siguieron dando su aprobación al gobierno por falta de auténticas alternativas.

Entre mayo y noviembre de 1925 (año del Jubileo) el Parlamento aprobó la ley que prohibía a los funcionarios pertenecer a asociaciones secretas. Se les obligó, incluidos los militares, a declarar por escrito ante sus superiores a qué asociaciones pertenecían. Se establecieron severas penas para quienes incumplieran dicha prohibición. La ley por lo tanto no fue retroactiva, ni tampoco se dirigía explícitamente contra la masonería.

Sin embargo, como respuesta a la misma, el Grande Oriente disolvió las logias, admitiendo así implícitamente que estaba al margen de lo previsto por la ley. Torrigiani instituyó un comité para gestionar los innumerables bienes inmuebles de la masonería, pertenecientes a la sociedad Urbs.

Tras algunos intentos de obtener de Mussolini el reconocimiento de una asociación que llevaba el nombre de San Juan de Escocia (nombre evidentemente masónico) Pelermi intentó lo mismo con la GldI.

En el informe de acompañamiento de la ley sobre pertenencia de los funcionarios a asociaciones, en el debate periodístico y en la historiografía, la masonería fue condenada por considerarse como algo superfluo para la vida nacional. Sus méritos pertenecían a un lejano pasado. Podían olvidarse. Así lo escribieron Mussolini y el historiador Gioacchino Volpe. 
Alessandro Luzio publicó dos importantes libros sobre La Massoneria e il Risorgimento italiano (Bologna, Zanichelli, 1925), muy documentados, pero al mismo tiempo muy polémicos contra el "espíritu masónico" y las "sectas", que habían resultado útiles en las luchas patrióticas del siglo XIX, como habían sostenido los poetas Giosue Carducci y Giovanni Pascoli, pero que ahora ya resultaban anacrónicas y antinacionales.

\section{Los masones durante el fascismo}

Durante el régimen fascista, el Estado nunca elaboró ninguna ley "contra la masonería". La pertenencia a las logias nunca se tipificó como delito. En cambio el régimen prohibió las asociaciones secretas. Como dijo el comunista Antonio Gramsci a la Cámara (mayo de 1925) la ley de asociaciones atacaba a la masonería (sin nombrarla) para prohibir los partidos de oposición. El Gran Oriente lo entendió tarde. La Gran Logia no fue contraria a dicha ley. La sufrió como un mal menor. En efecto, en 1926 el Parlamento declaró desposeídos de sus funciones a aquellos diputados que se habían ausentado del trabajo sin un motivo razonable, y que por lo tanto habían infringido lo dispuesto en el reglamento. Perdieron su cargo republicanos, socialdemócratas, socialistas y católicos. Algunos de ellos habían intentado volver a la cámara para la conmemoración de la reina Margherita (enero de 1926), pero fueron expulsados. Posteriormente se prohibieron los partidos y las asociaciones políticas, pero ni siquiera la nueva ley hacía referencia nominalmente a la masonería.

En Italia esa función de centro de agrupamiento de la clase dirigente hasta aquel momento habían desempeñado las logias fue asumida por el Rotary Club. El rey ostentaba su presidencia honorífica en 1925, colocándolos así en una posición segura.

El PNF no podía dirigir ninguna verdadera ofensiva general retroactiva contra la masonería puesto que entre sus líderes había muchos masones: Italo Balbo, Roberto Farinacci, el futuro ministro de Educación Nacional, Balbino Giuliano, Edmondo Rossoni (jefe de los sindicatos fascistas), Giacomo Acerbo (subsecretario de Presidencia), Giuseppe Belluzzo, ministro de Economía Nacional. Se sabía que muchos altos mandos militares estaban afiliados. En 1923-24 continuó la iniciación en las logias, en formas secretísimas, de autorizados exponentes del fascismo. Resulta emblemático el caso de Curzio Malaparte, célebre escritor, que fue iniciado en la GLdI pocos días antes del asesinato de Matteotti.

La mayoría de los cerca de 40.000 masones activos en 1925 no sufrió persecuciones ni sanciones particulares, públicas o privadas. El asalto de las escuadras a las logias formaba parte del periodo de la conquista del poder, fue expresión de conflictos entre "almas" distintas dentro del PNF y se agotó precisamente con la ley de noviembre de 1925 y la autodisolución de las dos obediencias. Algunos destacados masones desempeñaron funciones de primer orden en la dirección del país. Tal fue el caso de Alberto Beneduce, antiguo gran orador del GOdI, llamado por Mussolini para dirigir el Instituto para la Reconstrucción Industrial (IRI), la organización más importante de la economía italiana 
entre 1929 y los años setenta del pasado siglo, y para modernizar el Banco de Italia. Beneduce fue "mussoliniano" (no "fascista") porque consideraba que el Duce ejecutaba el programa de la masonería, a pesar de la Conciliación con la Santa Sede (11 de febrero de 1929).

En 1929 unas 130 cajas con documentos del GOdI cayeron en manos de la policía. Se desconoce cuál fue su suerte. Los mapas masónicos conservados en el Archivo Central del Estado constituyen una mínima parte de dichos documentos.

\section{¿Masonización del PNF?}

Así pues, el PNF no aniquiló a la masonería: la absorbió en su interior y en su imagen externa, adoptando símbolos, siglas, "héroes" y fechas memoriales. Si la Masonería había tenido un gran maestro, gran logia, consejo supremo, etc. el fascismo tuvo el Gran Consejo, los lictores, los seniori... Si la masonería había defendido sus orígenes caballerescos, especialmente templarios, el fascismo tuvo la Milicia Voluntaria de Seguridad Nacional con cónsules, centuriones y jefes-manípulos. El régimen hizo propias las fechas que en su momento veneraban los masones: la Navidad de Roma, el culto al Sol (exaltado por el himno "Sol que surges...") y por la exaltación de la juventud, de la virilidad, de la competitividad como deporte, sino como aniquilación del "enemigo".

En el seno del fascismo, vivieron ocultas corrientes esotéricas inspiradas por Arturo Reghini y sobre todo por Julius Evola, que fueron toleradas por Mussolini, el cual las utilizaba contra la Iglesia, y en especial contra la Acción Católica.

\section{Simul stabunt...}

Precisamente por dichos precedentes, con la crisis del régimen fascista, derrotado en la segunda guerra mundial, la masonería renació (no sin problemas) bajo el impulso de iniciados que habían "atravesado" el régimen, a veces perseguidos, a veces tolerados. Tal fue el caso de Domenico Maiocco, fundador de la Masonería Italiana Unificada (1943), reconocida por el Supremo Consejo de la Jurisdicción Sur de los Estados Unidos de América. Socialista y antifascista, arrestado y condenado a detención domiciliaria, aunque fue enseguida liberado. Maiocco mantuvo contactos ocultos con demócratas (Ivanoe Bonomi) y con líderes fascistas de orientación monárquica, próximos al rey, como Cesare Maria De Vecchi di Val Cismon. Gracias a él el monarca supo con antelación que el Gran Consejo habría impedido que Mussolini obtuviera el apoyo de la mayoría, pudiendo así organizar el "golpe de estado" del 25 de abril de 1943, con el apoyo de los militares en lugar de los fascistas, que culminó obligando a Mussolini a dimitir, siendo "arrestado" por los carabinieri.

Desde la creación de la República Social Italiana, en septiembre de 1943 y el centro-sur del país bajo tutela alemana, la masonería fue perseguida como agente del gobierno del sur e instrumento de los angloamericanos y de la "internacional judía", como 
ya habían indicado algunos enemigos de la masonería desde los años 1920-23 (Giovanni Preziosi, ex sacerdote, Francesco Gaeta, aspirante a masón decepcionado, Telesio Interlandi, director de "La Defensa de la Raza" y jefe de filas del racismo, iniciado en la GLdI cuando era estudiante...).

A partir de 1944 el Grande Oriente de Italia se reorganizó sobre bases prevalentemente antimonárquicas. En sus filas prevalecieron militantes republicanos, socialistas (anticomunistas) y "demócratas". Pero también nacieron muchas obediencias de otro signo, a menudo formadas por militares. Con la "liberación", la masonería en Italia dejó de estar prohibida, pero la Constitución reafirmó la prohibición de las asociaciones secretas, reiterada con la ley del 25 de enero de 1981, n. 17 (conocida como ley "contra la P2"), la cual sirvió como instrumento para muchos episodios de caza de brujas contra las logias masónicas, confirmando el clima de suspicacia que siguió existiendo y todavía subsiste en Italia en relación con la masonería. Una hostilidad que fue y va más allá de la matriz fascista, nacionalista, clerical o marxista-leninista, ya que hunde sus raíces en la "mentalidad": la sospecha de los poderes públicos en relación con las asociaciones "no reconocidas" y la necesidad de los ciudadanos de asociarse libremente.

\section{Conclusión}

Tras la caída del fascismo, el Partido Comunista, la Democracia Cristiana y el Movimiento Social Italiano ("heredero" del fascismo) prohibieron a sus militantes pertenecer a cualquier logia, si bien muchos entraron en ellas clandestinamente. Algunos de ellos, los más importantes, formaron parte de la logia "Propaganda Masónica n. 2" (P2), perteneciente al Grande Oriente de Italia y de las listas oficiales de las que mantenían relaciones regulares con la Gran Logia Unida de Inglaterra. Su "secretario de organización" y posteriormente venerable Licio Gelli, siempre se ha declarado estar orgulloso de su pasado fascista.

Es una prueba de la complejidad de la historia de la masonería en Italia.

\section{Bibliografía}

Conti, Fulvio. Storia della massoneria italiana dal Risorgimento al fascismo. Bologna, il Mulino, 2003.

Mola, Aldo A. La Masssoneria italiana tra iniziativa politica e conflitti interni, in Prima della temesta. Continuità e mutamenti nella politica e nella società italiana internazionale (1901-1914), a cura di Romano Ugolini, Atti del LXVI Congresso di storia del Risorgimento italiano. Roma: ISRI, 2015.

Mola, Aldo A. La Massoneria e la Grande Guerra. Roma: BastogiLibri, 2016. 